\title{
Ecological Methods of Assessing the Quality of the Environment in the Fluctuating Asymmetry of Birch Leaves
}

\author{
P.M. Mazurkin \\ Dr. Sc., Prof., Volga State University of Technology, Yoshkar-Ola, Russia, \\ kaf_po@mail.ru
}

\begin{abstract}
The methods of ecological assessment of the environmental quality of growing birch trees on fluctuating asymmetry of leaves after their stop in growth are briefly presented. In comparison with the average values of parameter measurements, each of the five leaves from at least three birches improves the accuracy of modeling and seven times reduces the complexity of measurements.

Key words: three birches, on five leaves, 10 parameters, factor analysis, correlation coefficient, strong regularities

\section{Introduction}

In environmental technology is gradually coming to an understanding of the need for modeling relationships between the parameters of structure of plant leaves identification method (Mazurkin, 2014a, b).

Our Russian inventions (Mazurkin, Semenova, 2016a, b, c, d, e, f) refers to the engineering of biology and bioindication of the environment quality measurements of the growth of the organs of different plant species, mostly woody plants, for example, samples in the form of leaves of birch trees with a simple and small leaf blades.

The technical result is an increase in the accuracy of indication of the quality of the surrounding birch leaves of the local environment, as well as simplifying and improving the performance of measurements of leaf parameters. Thus, we completely restore the principle of individuality of biological measurements on the geometry of fluctuation of each sheet.

\section{The Method of Measurement and Analysis}

Figure 1 shows a diagram of the dimensions of each sheet: 1 - the width of the left $b^{\prime}$ and right $b^{\prime \prime}$ halves of the leaf (the measurement was carried out in the middle of the leaf blade), mm; 2 - length $l_{\varkappa}^{\prime}$ and $l_{\varkappa}^{\prime \prime}$ the second from the base of the leaf veins of the second order, mm; 3 - distance $l_{o c H}^{\prime}$ and $l_{o c \mu}^{\prime \prime}$ between the bases of the first and second veins of second order, mm; 4 - distance $l_{\kappa}^{\prime}$ and $l_{\kappa}^{\prime \prime}$ between the ends of these veins, mm; 5 - angle $\alpha^{\prime}$ and $\alpha^{\prime \prime}$ between the main vein and the second from the base of the leaf vein of the second order. Collection of material should be carried out after stopping the growth of leaves (in the middle lane since July).
\end{abstract}


P.M. Mazurkin; Ecological Methods of Assessing the Quality of the Environment in the Fluctuating Asymmetry of Birch Leaves, Transactions on Networks and Communications, Volume 6 No. 3, June (2018); pp: 19-26

For environmental assessment of anthropogenic impact on the territory take at least three birches in approximately the same conditions of growth, with each birch take at least five leaves of different sizes on the part of the estimated area, then the measurement of the five parameters of the sheet is carried out with the use of geodetic protractor with the price of dividing the measuring scale of $0.1 \mathrm{~mm}$, with all at least 15 leaves are taken for the population of individual individuals, therefore, the table of measurement results without averaging the measured values is further compiled, and the resulting sample is statistically simulated and subjected to factor analysis to identify binary relations between 10 indicators, with all 100 biotechnical laws identified in the software environment CurveExpert-1.40 by the formula of the form

$$
y=a_{1} x^{a_{2}} \exp \left(-a_{3} x^{a_{4}}\right)+a_{5} x^{a_{6}} \exp \left(-a_{7} x^{a_{8}}\right)
$$

where $y$ - an indicator or a dependent quantitative factor (10 parameters for five indicators from two halves of the sheet); $x$ - an explanatory variable or an influencing factor (the same 10 parameters from each sheet); $a_{1} \ldots a_{8}$ - the model parameters obtained by identification.

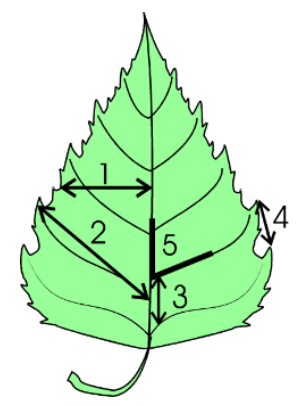

Figure 1

Corresponding Author: Peter Mathveevich Mazurkin, Volga State University of Technology, 424000, the Republic of Mari El, Yoshkar-Ola, Lenin Sq., b. 3, Email: kaf_po@mail.ru

According to the results of factor analysis by identifying binary relations between 10 indicators perform environmental assessment of the territory by the coefficient of correlation variation, and then from 100 biotechnical laws are selected having a correlation coefficient of at least 0,7 and consider pairwise five parameters of the sheet, as well as environmental assessment is carried out by differences between the structure and parameters of specific equations.

The results of the measurements in a clean area of the city of Zvenigovo Republic of Mari El

According to the principle of individuality of each leaf, the results of measuring the parameters of 15 leaves of only three birches in a clean area are listed in table 1. 
Table 1. Results of measurements of birch leaves growing in the clean zone of the city

(on 5 of leaves with 3 plants)

\begin{tabular}{|c|c|c|c|c|c|c|c|c|c|c|c|}
\hline \multirow[b]{2}{*}{ № trees } & \multirow[b]{2}{*}{$\begin{array}{c}\text { № } \\
\text { sheet }\end{array}$} & \multicolumn{2}{|c|}{ Width $b, \mathrm{~mm}$} & \multicolumn{2}{|c|}{ Length, $l_{\varkappa}, \mathrm{mm}$} & \multicolumn{2}{|c|}{ Distance $l_{o c h}, \mathrm{~mm}$} & \multicolumn{2}{|c|}{ Distance $l_{\kappa}, \mathrm{mm}$} & \multicolumn{2}{|c|}{ Corner $\alpha$, degree } \\
\hline & & $\begin{array}{c}\text { left } \\
b^{\prime} \\
\end{array}$ & $\begin{array}{c}\text { right } \\
b^{\prime \prime}\end{array}$ & $\begin{array}{l}\text { left } \\
l_{\varkappa}^{\prime} \\
\end{array}$ & $\begin{array}{c}\text { right } \\
l_{\varkappa}^{\prime \prime} \\
\end{array}$ & $\begin{array}{l}\text { left } \\
l_{\text {och }}^{\prime} \\
\end{array}$ & $\begin{array}{c}\text { right } \\
l_{\text {och }}^{\prime \prime} \\
\end{array}$ & $\begin{array}{c}\text { left } \\
l_{\kappa}^{\prime} \\
\end{array}$ & $\begin{array}{c}\text { right } \\
l_{\kappa}^{\prime \prime} \\
\end{array}$ & $\begin{array}{c}\text { left } \\
\alpha^{\prime} \\
\end{array}$ & $\begin{array}{c}\text { right } \\
\alpha^{\prime \prime}\end{array}$ \\
\hline \multirow{5}{*}{1} & 1 & 18 & 17 & 32 & 30 & 8 & 8 & 10 & 10 & 30 & 28 \\
\hline & 2 & 19 & 21 & 33 & 36 & 9 & 8 & 12 & 13 & 34 & 39 \\
\hline & 3 & 22 & 19 & 36 & 32 & 6 & 8 & 14 & 14 & 37 & 33 \\
\hline & 4 & 17 & 20 & 31 & 31 & 5 & 7 & 13 & 11 & 44 & 34 \\
\hline & 5 & 16 & 17 & 29 & 31 & 12 & 11 & 12 & 16 & 30 & 31 \\
\hline \multirow{5}{*}{2} & 6 & 16 & 17 & 28 & 29 & 5 & 6 & 10 & 10 & 34 & 37 \\
\hline & 7 & 17 & 15 & 31 & 29 & 3 & 2 & 10 & 9 & 43 & 37 \\
\hline & 8 & 18 & 18 & 33 & 32 & 5 & 5 & 11 & 9 & 37 & 36 \\
\hline & 9 & 16 & 19 & 28 & 32 & 5 & 5 & 10 & 11 & 38 & 42 \\
\hline & 10 & 23 & 21 & 37 & 40 & 5 & 6 & 12 & 13 & 38 & 37 \\
\hline \multirow{5}{*}{3} & 11 & 18 & 19 & 31 & 33 & 5 & 4 & 13 & 12 & 49 & 49 \\
\hline & 12 & 17 & 16 & 30 & 30 & 5 & 4 & 10 & 11 & 46 & 43 \\
\hline & 13 & 23 & 21 & 40 & 40 & 4 & 3 & 15 & 15 & 48 & 42 \\
\hline & 14 & 16 & 20 & 37 & 35 & 6 & 8 & 13 & 12 & 44 & 44 \\
\hline & 15 & 23 & 22 & 37 & 40 & 6 & 7 & 14 & 15 & 46 & 44 \\
\hline
\end{tabular}

Full factorial analysis includes 10 factors and $102=100$ factor relations. For all of them the equation has the form of (1).

The correlation matrix of the factor analysis for assessment of a condition of the environment is given in table 2.

Table 2. Correlation matrix of the full factorial analysis of plastic signs of leaves of a birch for assessment of a condition of the environment

\begin{tabular}{|c|c|c|c|c|c|c|c|c|c|c|c|c|}
\hline \multirow{2}{*}{$\begin{array}{l}\text { The influencing factors } \\
x\end{array}$} & \multicolumn{10}{|c|}{ Dependent factors (indicators $y$ ) } & \multirow{2}{*}{$\begin{array}{l}\text { Sum } \\
\sum r_{x}\end{array}$} & \multirow{2}{*}{$\begin{array}{c}\text { Place } \\
I_{x}\end{array}$} \\
\hline & $b^{\prime}$ & $b^{\prime \prime}$ & $l_{\varkappa}^{\prime}$ & $l_{\varkappa}^{\prime \prime}$ & $l_{o c H}^{\prime}$ & $l_{O C H}^{\prime \prime}$ & $l_{\kappa}^{\prime}$ & $l_{\kappa}^{\prime \prime}$ & $\alpha^{\prime}$ & $\alpha^{\prime \prime}$ & & \\
\hline Width $b^{\prime}, \mathrm{mm}$ & 1 & 0,6530 & 0,8105 & 0,8210 & 0,1700 & 0,0905 & 0,6621 & 0,6639 & 0,2740 & 0,1222 & 5,2672 & 6 \\
\hline Width $b^{\prime \prime}, \mathrm{mm}$ & 0,7179 & 1 & 0,7139 & 0,9185 & 0,2413 & 0,4052 & 0,7404 & 0,5721 & 0,4132 & 0,3913 & 6,1138 & 2 \\
\hline Length $l_{\mathscr{H}}^{\prime}, \mathrm{mm}$ & 0,8058 & 0,6806 & 1 & 0,8340 & 0,2299 & 0,1746 & 0,7572 & 0,5652 & 0,4036 & 0,2785 & 5,7294 & 5 \\
\hline Length $l_{\mathscr{H}}^{\prime \prime}, \mathrm{mm}$ & 0,8175 & 0,9144 & 0,8133 & 1 & 0,3181 & 0,3546 & 0,7190 & 0,6315 & 0,3420 & 0,4419 & 6,3523 & 1 \\
\hline Distance $l_{o c h}^{\prime}, \mathrm{mm}$ & 0,2712 & 0,4867 & 0,3173 & 0,2346 & 1 & 0,8960 & 0,1701 & 0,4796 & 0,6639 & 0,4962 & 5,0156 & 8 \\
\hline Distance $l_{o c H}^{\prime \prime}, \mathrm{mm}$ & 0,2776 & 0,4977 & 0,0818 & 0,2226 & 0,9262 & 1 & 0,2068 & 0,5337 & 0,6369 & 0,5953 & 4,9786 & 9 \\
\hline Distance $l_{K}^{\prime}, \mathrm{mm}$ & 0,5290 & 0,7585 & 0,7693 & 0,6791 & 0,4647 & 0,3308 & 1 & 0,7367 & 0,5290 & 0,2888 & 6,0859 & 3 \\
\hline Distance $l_{\kappa}^{\prime \prime}, \mathrm{mm}$ & 0,5851 & 0,7079 & 0,4921 & 0,6560 & 0,5585 & 0,4618 & 0,7553 & 1 & 0,2643 & 0,4204 & 5,9014 & 4 \\
\hline Corner $\alpha^{\prime}$, degree & 0,2573 & 0,3117 & 0,3686 & 0,3450 & 0,7079 & 0,6413 & 0,4834 & 0,1871 & 1 & 0,7796 & 5,0819 & 7 \\
\hline Corner $\alpha^{\prime \prime}$, degree & 0,1405 & 0,3644 & 0,2091 & 0,4233 & 0,4177 & 0,5406 & 0,2787 & 0,1283 & 0,7796 & 1 & 4,2822 & 10 \\
\hline $\operatorname{Sum} \Sigma r_{y}$ & 5,4019 & 6,3749 & 5,5759 & 6,1341 & 5,0343 & 4,8954 & 5,773 & 5,4981 & 5,3065 & 4,8142 & 54,8083 & - \\
\hline Place $I_{y}$ & 6 & 1 & 4 & 2 & 8 & 9 & 3 & 5 & 7 & 10 & - & 0,5480 \\
\hline
\end{tabular}


P.M. Mazurkin; Ecological Methods of Assessing the Quality of the Environment in the Fluctuating Asymmetry of Birch Leaves, Transactions on Networks and Communications, Volume 6 No. 3, J une (2018); pp: 19-26

The coefficient of correlation variation of the ecological set of 15 leaves ( 5 leaves from 3 trees) is 54,8083 $/ 10^{2}=0,5480$. This criterion is used when comparing different sampling sites of birch leaves. In comparison with table 2 , variability in fluctuating asymmetry increased significantly, as 0.5480 .

\section{Analysis of Binary Relations between Factors}

To do this, we exclude monarny relations from the data 1 , we leave only binary relations with strong factorial relations (table. 3). There are 22 strong binary dependencies left. The formula $l_{\text {оси }}^{\prime \prime} l_{\text {оси has the }}^{\prime}$ highest strength. The distance between the bases of the first and second veins on the right side of the leaves most affects the distance between the bases of the first and second veins on the left side of the leaves.

Table 3. Correlation matrix of strong binary relations of plastic signs of birch leaves under condition $r \geq 0,7$

\begin{tabular}{|c|c|c|c|c|c|c|c|c|c|c|}
\hline \multirow{2}{*}{$\begin{array}{l}\text { The influencing } \\
\text { factors } x\end{array}$} & \multicolumn{10}{|c|}{ Dependent factors (indicators $y$ ) } \\
\hline & $b^{\prime}$ & $b^{\prime \prime}$ & $l_{\varkappa}^{\prime}$ & $l_{\varkappa}^{\prime \prime}$ & $l_{\text {ocH }}^{\prime}$ & $l_{\text {och }}^{\prime \prime}$ & $l_{k}^{\prime}$ & $l_{\kappa}^{\prime \prime}$ & $\alpha^{\prime}$ & $\alpha^{\prime \prime}$ \\
\hline Width $b^{\prime}, \mathrm{mm}$ & & & 0,8105 & 0,8210 & & & & & & \\
\hline Width $b^{\prime \prime}, \mathrm{mm}$ & 0,7179 & & 0,7139 & 0,9185 & & & 0,7404 & & & \\
\hline Length $l_{\mathscr{K}}^{\prime}, \mathrm{mm}$ & 0,8058 & & & 0,8340 & & & & & & \\
\hline Length $l_{\mathscr{K}}^{\prime \prime}, \mathrm{mm}$ & 0,8175 & 0,9144 & 0,8133 & & & & 0,7190 & & & \\
\hline Distance $l_{o c H}^{\prime}, \mathrm{mm}$ & & & & & & 0,8960 & & & & \\
\hline Distance $l_{o c h}^{\prime \prime}, \mathrm{mm}$ & & & & & 0,9262 & & & & & \\
\hline Distance $l_{k}^{\prime}, \mathrm{mm}$ & & 0,7585 & 0,7693 & & & & & 0,7367 & & \\
\hline Distance $l_{\kappa}^{\prime \prime}, \mathrm{mm}$ & & 0,7079 & & & & & 0,7553 & & & \\
\hline Corner $\alpha^{\prime}$, degree & & & & & 0,7079 & & & & & 0,7796 \\
\hline Corner $\alpha^{\prime \prime}$, degree & & & & & & & & & 0,7796 & \\
\hline
\end{tabular}

For example, figure 2 shows a graph of the effect of $l_{\text {осн }}^{\prime \prime} \rightarrow l_{\text {осн }}^{\prime}$ the distance between the bases of the first and second veins on the right side of the leaves by the distance between the bases of the first and second veins on the left side of the leaves when measured by the proposed method on 15 leaves in three birches. Figure 3 shows a graph of the result $b^{\prime \prime} \rightarrow l^{\prime \prime}$ of the influence of the width on the right side of the leaves on the length of the second vein on the right side of the leaves. 


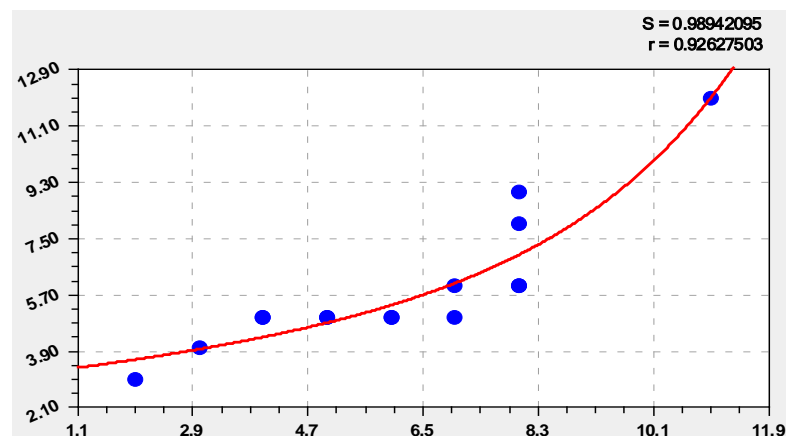

Figure 2. Graph of the formula $l_{\text {oCH }}^{\prime \prime} \rightarrow l_{\text {осн }}^{\prime}$

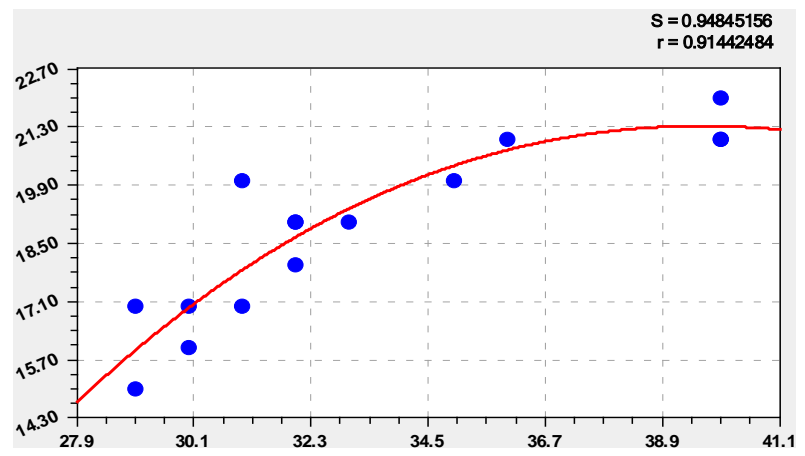

Figure 4. Graph of the formula $l_{\mathscr{K}}^{\prime \prime} \rightarrow b^{\prime \prime}$

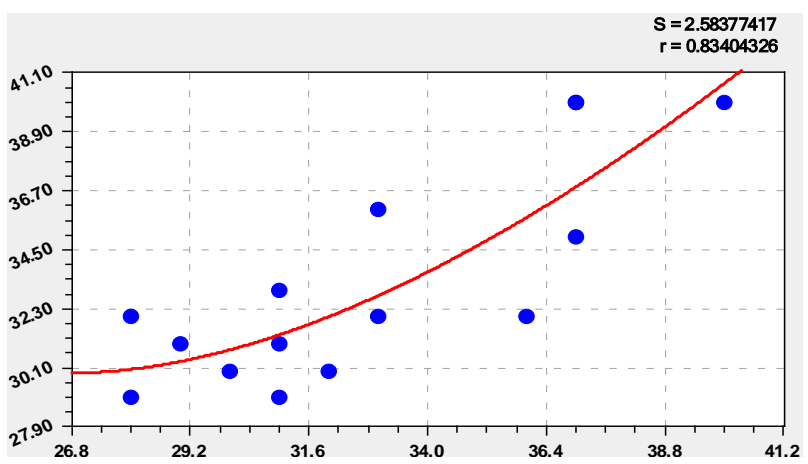

Figure 6. Graph of the formula $l_{\varkappa}^{\prime} \rightarrow l_{\mathscr{F}}^{\prime \prime}$

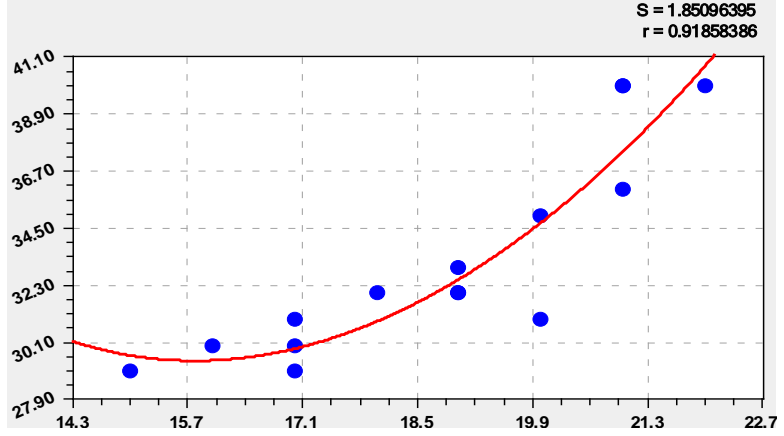

Figure 3. Graph of the formula $b^{\prime \prime} \rightarrow l_{\mathscr{x}}^{\prime \prime}$

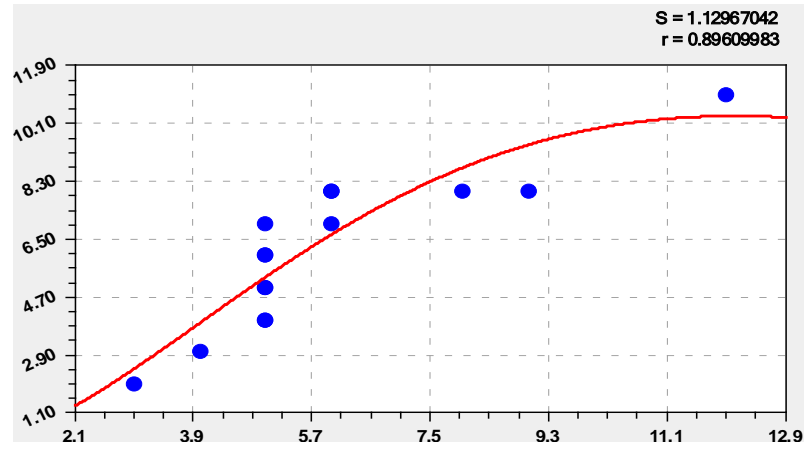

Figure 5. Graph of the formula $l_{\mathrm{ocH}}^{\prime} \rightarrow l_{\mathrm{ocH}}^{\prime \prime}$

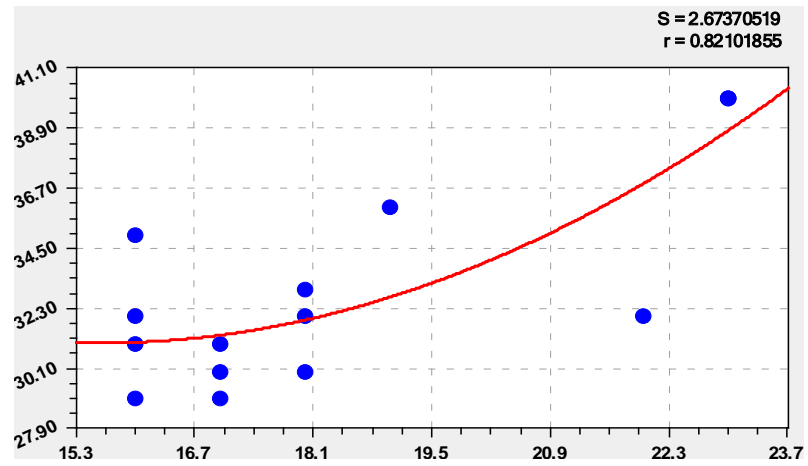

Figure 7. Graph of the formula $b^{\prime} \rightarrow l_{\mathscr{K}}^{\prime \prime}$

On figure 4 - graph of the result $l_{\varkappa}^{\prime \prime} \rightarrow b^{\prime \prime}$ influence of the length of the second vein on the right side of the leaves on the width on the right side of the leaves. On a figure 5 shows the graph of the result $l_{\text {оси }}^{\prime} \rightarrow$ $l_{\text {оси }}^{\prime \prime}$ of the influence of the distance between the bases of the first and second veins on the left side of the leaves on the distance between the bases of the first and second veins on the right side of the leaves. On a figure 6 - graph of the result $l_{\varkappa}^{\prime} \rightarrow l_{\varkappa}^{\prime \prime}$ influence of the length of the second vein on the left side of the leaves on the length of the second vein on the right side of the leaves. On a figure 7 shows the graph of $b^{\prime} \rightarrow l_{\varkappa}^{\prime \prime}$ effect of width on the left side of leaves on the length of the second vein on the right side of leaves

\section{Comparison of the Proposed Methods with the Prototype}

Thus, the comparison shows that the proposed information technology for processing the values of the same parameters in individual leaves 57 / $22=2,59$ times stricter than the prototype. 
P.M. Mazurkin; Ecological Methods of Assessing the Quality of the Environment in the Fluctuating Asymmetry of Birch Leaves, Transactions on Networks and Communications, Volume 6 No. 3, J une (2018); pp: 19-26

The correlation coefficient is also $0,7538 / 0.5480=1,38$ times less, which indicates better variability. Therefore, it can be concluded that the adoption of the arithmetic mean values of the parameters of birch leaves up to 100 (10 trees for 10 leaves) is artificial, smoothing the variability of fluctuating asymmetry. In reality, it is much more variable.

All 22 strong links in table 3 are arranged without the loss of a row and form a geometric pattern. This fact also points to the application of the principle of individuality, that is, without averaging the results of environmental measurements.

Write out the formula 22 binary factor strong ties, ranging in table 4 in descending order of correlation coefficient.

Table 4. Options patterns binary strong ties factors

\begin{tabular}{|c|c|c|c|c|c|c|c|c|c|c|}
\hline \multirow{3}{*}{$\begin{array}{l}\text { № } \\
\Pi / \Pi\end{array}$} & \multirow{3}{*}{$x \rightarrow y$} & \multicolumn{8}{|c|}{$y=a_{1} x^{a_{2}} \exp \left(-a_{3} x^{a_{4}}\right)+a_{5} x^{a_{6}} \exp \left(-a_{7} x^{a_{8}}\right)$} & \multirow{3}{*}{$\begin{array}{c}\text { Correlation } \\
\text { coefficient } \\
r\end{array}$} \\
\hline & & \multicolumn{4}{|c|}{ The first component } & \multicolumn{4}{|c|}{ Second component } & \\
\hline & & $a_{1}$ & $a_{2}$ & $a_{3}$ & $a_{4}$ & $a_{5}$ & $a_{6}$ & $a_{7}$ & $a_{8}$ & \\
\hline 1 & $l_{O C H}^{\prime \prime} \rightarrow l_{O C H}^{\prime}$ & 3,071555 & 0 & 0,071176 & 1 & 0,037407 & 0,39827 & 0,36397 & 1 & 0,9262 \\
\hline 2 & $b^{\prime \prime} \rightarrow l_{\varkappa}^{\prime \prime}$ & 216,90035 & 0 & 0,18129 & 1 & 0,48931 & 0,82839 & 0,079967 & 1 & 0,9185 \\
\hline 3 & $l_{\mathscr{H}}^{\prime \prime} \rightarrow b^{\prime \prime}$ & 0,13005 & 2,26719 & 0,057208 & 1 & 35,24084 & 0 & 0 & 1 & 0,9144 \\
\hline 4 & $l_{\text {ocH }}^{\prime} \rightarrow l_{\text {ocH }}^{\prime \prime}$ & 0,37763 & 2,21272 & 0,18243 & 1 & 0 & 0 & 0 & 1 & 0,8960 \\
\hline 5 & $l_{\varkappa}^{\prime} \rightarrow l_{\mathscr{H}}^{\prime \prime}$ & 285,55703 & 0 & 0,13188 & 1 & 0,61588 & 0,94539 & 0,016692 & 1 & 0,8340 \\
\hline 6 & $b^{\prime} \rightarrow l_{\varkappa}^{\prime \prime}$ & 83,922 & 0 & 0,10854 & 1 & 0,62999 & 0,88169 & 0,050474 & 1 & 0,8210 \\
\hline 7 & $l_{\varkappa}^{\prime \prime} \rightarrow b^{\prime}$ & 429,19236 & 0 & 0,15290 & 1 & 0,25493 & 0,89348 & 0,028748 & 1 & 0,8175 \\
\hline 8 & $l_{\varkappa}^{\prime \prime} \rightarrow l_{\varkappa}^{\prime}$ & 9,96212 & 0 & 0,019433 & 1 & 0,74876 & 1,025059 & 0,00041489 & 1 & 0,8133 \\
\hline 9 & $b^{\prime} \rightarrow l_{\varkappa}^{\prime}$ & 45,87364 & 0 & 0,081235 & 1 & 0,85588 & 0,92382 & 0,029908 & 1 & 0,8105 \\
\hline 10 & $l_{\mathscr{H}}^{\prime} \rightarrow b^{\prime}$ & 0,0097932 & 2,10278 & 0,0099842 & 1 & 7,62307 & 0 & 0 & 1 & 0,8058 \\
\hline 11 & $\alpha^{\prime} \rightarrow \alpha^{\prime \prime}$ & 5,52381 & 0 & 0,0057460 & 1 & 2,68220 & 0,62964 & 0,0054722 & 1 & 0,7796 \\
\hline 12 & $\alpha^{\prime \prime} \rightarrow \alpha^{\prime}$ & 1,99219 & 0 & 0,039772 & 1 & 1,065425 & 1,035282 & 0,010853 & 1 & 0,7796 \\
\hline 13 & $l_{\kappa}^{\prime} \rightarrow l_{\varkappa}^{\prime}$ & 33,97637 & 0 & 0,041107 & 1 & 0,39111 & 0,61879 & 0,15405 & 1 & 0,7693 \\
\hline 14 & $l_{\kappa}^{\prime} \rightarrow b^{\prime \prime}$ & 0,098318 & 3,010187 & 0,19554 & 1 & 2,58419 & 0 & 0 & 1 & 0,7585 \\
\hline 15 & $l_{\kappa}^{\prime \prime} \rightarrow l_{\kappa}^{\prime}$ & 0,017059 & 3036064 & 0,19256 & 1 & 4,97922 & 0 & 0 & 1 & 0,7553 \\
\hline 16 & $b^{\prime \prime} \rightarrow l_{\kappa}^{\prime}$ & 110,10051 & 0 & 0,40834 & 1 & 0,60848 & 1,01504 & 0,00041684 & 1 & 0,7404 \\
\hline 17 & $l_{\kappa}^{\prime} \rightarrow l_{\kappa}^{\prime \prime}$ & 4,27876 & 0,78319 & 0,023133 & 1 & 10,46382 & 0 & 0 & 1 & 0,7367 \\
\hline 18 & $l_{\mathscr{H}}^{\prime \prime} \rightarrow l_{\kappa}^{\prime}$ & 0,087963 & 2,27808 & 0,058024 & 1 & 25,015367 & 0 & 0 & 1 & 0,7190 \\
\hline 19 & $b^{\prime \prime} \rightarrow b^{\prime}$ & 125,22754 & 0 & 0,16146 & 1 & 0,13403 & 0,73296 & 0,12324 & 1 & 0,7179 \\
\hline 20 & $b^{\prime \prime} \rightarrow l_{\mathscr{H}}^{\prime}$ & 138,011555 & 0 & 0,16128 & 1 & 0,75209 & 0,91987 & 0,043949 & 1 & 0,7139 \\
\hline 21 & $l_{\kappa}^{\prime \prime} \rightarrow b^{\prime \prime}$ & 0,14397 & 3,050669 & 0,22213 & 1 & 0 & 0 & 0 & 1 & 0,7079 \\
\hline 22 & $\alpha^{\prime} \rightarrow l_{o c H}^{\prime}$ & 33,68506 & 0 & 0,044599 & 1 & 0 & 0 & 0 & 1 & 0,7079 \\
\hline
\end{tabular}

Matrix representation of the model (1) is compact, but for clarity we will write the first three binary relationships separately in the form of formulas: 
- effect of the distance between the bases of the first and second veins on the right side of the leaves on the distance between the bases of the first and second veins (Figure 2) on the left side of the leaves

$$
\begin{gathered}
l_{\text {ocH }}^{\prime}=3,071555 \exp \left(0,071176 l_{\text {ocH }}^{\prime \prime}\right)+ \\
+0,037407 l_{\text {och }}^{\prime \prime} 0,39827 \exp \left(0,39827 l_{\text {ocH }}^{\prime \prime}\right)
\end{gathered}
$$

- effect of width on the right side of the leaves on the length of the second vein (Figure 3 ) on the right side of the leaves

$$
l_{\varkappa}^{\prime \prime}=216,90035 \exp \left(0,18129 b^{\prime \prime}\right)+\quad+0,48931 b^{\prime \prime, 82839} \exp \left(0,079967 b^{\prime \prime}\right) ;
$$

- the effect of the length of the second vein on the right side of the leaves on the width on the right (Figure. 4) side of the leaves

$$
b^{\prime \prime}=0,13005 l_{\varkappa}^{\prime \prime 2,26719} \exp \left(-0,057208 l_{\varkappa}^{\prime \prime}\right)-35,24084
$$

\section{Conclusion}

Thus, fluctuating asymmetry can be captured by statistical modelling from a much smaller volume of measurements. The smallest volume of measurements we recommend 15 (three trees of five different leaf sizes from different places). This will reduce the volume of measurements $100 / 15 \approx 7$ times. However, this increases the accuracy of the analysis of fluctuating asymmetry.

The advantage of the proposed method is the technical simplicity of execution, since the equipment requires only a measuring pair of compasses and surveying protractor with scale division 0,1 mm. Therefore, the invention can be widely implemented in school environmental clubs, school forestries, and even kindergartens, as well as in geographical and other expeditions with additional study of the quality of the territory on the properties of the leaves of the birch trees.

\section{REFERENCES}

[1] Mazurkin, P.M. Method of identification. (2014). International Multidisciplinary Scientific GeoConference Surveying Geology and Mining Ecology Management, SGEM, $1 \quad$ (6), pp. 427-434. https://www.scopus.com/inward/record.uri?eid=2-s2.0$\underline{84946541076 \& \text { partnerID }=40 \& m d 5=72 a 3 f c c e 31 b 20 f 2 e 63 e 4 f 23 e 9 a 8 a 40 e 3}$

[2] Mazurkin, P.M. Identification of the wave patterns of behavior. (2014). International Multidisciplinary Scientific GeoConference Surveying Geology and Mining Ecology Management, SGEM, 1 (6), pp. 373-380. https://www.scopus.com/inward/record.uri?eid=2-s2.084946550468\&partnerID=40\&md5=0fd8f91ed5b1f0592fc587e5ffb14e51

[3] Patent 2549779 Russian Federation, IPC A 01 G 23 / 00 (2006.01). The way the environmental dimension of the sides of the birch of the municipal Park in the fluctuating asymmetry of leaves / Mazurkin, P.M., Semenov D.V.; applicant and patentee Volga state University of technology No. 2013136883/13; stated 06.08.2013; published 27.04.2015. Bulletin No. 12. http://www1.fips.ru/Archive/PAT/2015FULL/2015.04.27/DOC/RUNWC2/000/000/002/549/779/document.pdf

[4] Patent 2556980 Russian Federation, IPC A 01 G 23 / 00 (2006.01). Method of ecological measurement of birch bark on fluctuating asymmetry of leaves / Mazurkin, P.M., Semenova D.V.; applicant and patentee Volga state 
P.M. Mazurkin; Ecological Methods of Assessing the Quality of the Environment in the Fluctuating Asymmetry of Birch Leaves, Transactions on Networks and Communications, Volume 6 No. 3, June (2018); pp: 19-26 technological University №2013136716/13; announced 06.08.2013; published 20.07.2015. Bulletin No. 20. http://www1.fips.ru/Archive/PAT/2015FULL/2015.07.20/DOC/RUNWC2/000/000/002/556/980/document.pdf

[5] Patent 2556985 Russian Federation, IPC A 01 G 23 / 00 (2006.01). Method of comparative indication on fluctuating asymmetry of birch leaves / Mazurkin, P.M., Semenova D.V.; applicant and patentee Volga state technological University №2013136813/13; announced 06.08.2013; published 20.07.2015. Bulletin No. 20. http://www1.fips.ru/Archive/PAT/2015FULL/2015.07.20/DOC/RUNWC2/000/000/002/556/985/document.pdf

[6] Patent 2556987 Russian Federation, IPC A 01 G 23 / 00, A 01 G 7/00 (2006.01). The method of measuring fluctuating asymmetry of birch leaves / Mazurkin, P. M., Semenov D. V.; applicant and patentee Volga state University of technology No. 2013130471/13; stated 02.07.2013; published 20.07.2015. Bulletin No. 20. http://www1.fips.ru/Archive/PAT/2015FULL/2015.07.20/DOC/RUNWC2/000/000/002/556/987/document.pdf

[7] Patent 2569748 Russian Federation, IPC G 01 N 33 / 46 (2006.01). Method a comparative indication of contamination of the air in the fluctuating asymmetry of birch leaves / Mazurkin, P. M., Semenov D. V.; applicant and patentee Volga state University of technology No. 2013134056/13; stated 19.07.2013; published on 27.11.2015. Bulletin No. 33. http://www.fips.ru/Archive/PAT/2015FULL/2015.11.27/DOC/RUNWC2/000/000/002/569/748/document.pdf

[8] Patent 2580647 Russian Federation, IPC G 01 N 33 / 46 (2006.01). Method of indication of air pollution by fluctuating asymmetry of birch leaves / Mazurkin, P.M., Semenova D.V.; applicant and patentee Volga state technological University №2013136714/15; declared 06.11.2013; published 27.05.2015. Bulletin No. 15. http://www.fips.ru/Archive4/PAT/2016FULL/2016.04.10/DOC/RUNWC2/000/000/002/580/647/document.pdf 